\title{
AI... VOU FAZER UM TESTE! CONSIDERAÇÕES EM TORNO DA ANSIEDADE A EXAMES
}

\author{
Lisete dos Santos Mendes Mónico \\ Universidade de Coimbra, Faculdade de Psicologia e de Ciências da Educação \\ Coimbra, Portugal \\ lisete.monico@fpce.uc.pt \\ Paulo Alexandre de Castro \\ Universidade Federal de Goiás, Regional Catalão \\ Goiás, Brasil \\ padecastro@gmail.com
}

http://dx.doi.org/10.17060/ijodaep.2015.n1.v1.69

Fecha de Recepción: 7 Febrero 2015

Fecha de Admisión: 30 Marzo 2015

\begin{abstract}
RESUMO
A ansiedade a exames é um importante problema pessoal e social, que influencia o desempenho e o próprio desenvolvimento pessoal. 0 presente artigo tem por objetivo refletir acerca da ansiedade a exames e da importância de diversas variáveis associadas às dificuldades sentidas por alunos ao nível da ansiedade de desempenho aos exames e, consequentemente, do seu rendimento escolar. 0 artigo começa por delimitar conceptualmente e explanar a sintomatologia e variáveis associadas à ansiedade em exames em crianças, adolescentes e adultos. Evidenciam-se as componentes emocional, fisiológica e cognitiva e apontam-se alguns modelos compreensivo para a ansiedade a exames. Seguidamente, referem-se possíveis causas subjacentes ao desempenho escolar, com particular ênfase nas variáveis sociocognitivas. Discute-se a natureza complexa e multidimensional deste distúrbio de ansiedade e 0 estilo atribucional dos alunos com ansiedade a exames. Conclui-se que a ansiedade às situações de exames não deve ser encarada como uma mera característica da situação ou do estudante. Ela resulta não das propriedades objetivas da situação, mas antes da interpretação ou avaliação cognitiva que o aluno faz da mesma.

Palavras-chave: Ansiedade a exames; Ansiedade de desempenho; Ansiedade; Rendimento escolar
\end{abstract}

As pessoas com níveis disfuncionais de ansiedade a exames são vítimas de grande sofrimento, do excesso de tempo gasto a estudar e de níveis mais baixos de performance (Sarason \& Sarason, 1990). Numa sociedade apologista do sucesso baseado na concorrência, onde as pessoas são catalogadas não por uma análise real das suas potencialidades mas antes pelos seus comportamentos 


\section{AI... VOU FAZER UM TESTE! CONSIDERAÇÕES EM TORNO DA ANSIEDADE A EXAMES}

manifestos, indivíduos com ansiedade a exames são um exemplo importante de pessoas a quem é necessário cada vez mais prestar apoio (Dendato \& Diener, 1986).

Segundo March (1995), a ansiedade em situações de avaliação, como em qualquer outro tipo de ansiedade, é uma emoção que tem desempenhado um papel fundamental na adaptação aos problemas criados pelo ambiente. A ansiedade, "quando se torna intensa, inibe comportamentos complexos como os que são requeridos num acto de exame, em que é preciso, entre outros aspectos, relembrar a matéria, expor de uma forma lógica e relacionar os acontecimentos com lógica." (Dias \& Vaz Serra, 1988, p. 80). Neste sentido, compreende-se que os alunos com elevada ansiedade a exames sintam dificuldades em ultrapassar com êxito estas tarefas.

0 presente artigo tem por objetivo refletir acerca da ansiedade a exames e da importância de diversas variáveis associadas às dificuldades sentidas por alunos ao nível da ansiedade de desempenho aos exames e, consequentemente, do seu rendimento escolar.

$A$ ansiedade a exames corresponde à ansiedade de desempenho e engloba-se no diagnóstico de Fobia Social (correspondente no DSM IV à classificação 300.23 e na CID-10 ao código 41.9). A reação de fobia social é o receio de não causar uma impressão positiva ou de ser avaliado negativamente pelos outros em situações de interação social, daí a ansiedade a exames se englobar na classificação diagnóstica de fobia social (Cruz, 1988). 0 núcleo da fobia social é, portanto, o indivíduo recear comportar-se em situações sociais de forma embaraçosa ou humilhante, o que leva a que os outros o vejam como incapaz o que, por sua vez, conduz a uma baixa autoestima.

Tem-se verificado que as queixas somáticas de crianças estão muito ligadas a casos de ansiedade a exames, o que por vezes se torna difícil de diagnosticar, dado o teor fisiológico das queixas, na maioria das vezes não associadas a fatores psicológicos (March, 1995). Constatou-se que, em situações de cariz mais ansiógeno, as crianças com ansiedade a exames não referiam a ocorrência de cognições negativas de modo tão frequente como os adultos. Afirmavam que também, numa percentagem largamente superior às das crianças na população geral, que cada dia que passava se defrontavam com acontecimentos ansiógenos para os quais não possuíam controlo (March, 1995). A escola é por estas crianças encarada como assustadora, ocorrendo nela local cerca de $60 \%$ dos acontecimentos indutores de stress. Quando eventos de tal natureza ocorrem, estas crianças têm maiores probabilidades de Ihes responder negativamente, quando comparadas com outras crianças. Ainda na escola, verificam-se outras situações que desencadeiam ansiedade: trata-se dos encontros lúdicos com os companheiros. Em geral, os sintomas físicos são relatados nestas crianças em $70.8 \%$ dos casos como palpitações, em $66.7 \%$ instabilidade, em $62.5 \%$ flashes de frio e calor, em $54.2 \%$ sudação e em $54.2 \%$ náuseas (March, 1995). Não obstante esta ativação do sistema nervoso fisiológico, a maior parte das respostas de coping negativas, envolvem comportamentos de evitamento. Em adolescentes, a ruborização é uma manifestação do sistema fisiológico que os incomoda substancialmente. Um adolescente com fobia social, ao corar frente aos colegas, pensa que estes o consideram envergonhado, imaturo e infantil (Gouveia, 1997).

Se perguntarmos qual a idade mais provável de início da ansiedade a exames, diríamos a adolescência. Contudo, Marsh (1995) afirma que os medos sociais e os défices na performance escolar aparecem, espontaneamente, durante a infância. De facto, os indivíduos adultos com ansiedade de desempenho descrevem-se como sendo, já desde a infância, ansiosos e envergonhados. Não obstante outros poderem perceber estas crianças como socialmente ansiosas e com comportamentos inibitórios, estas podem perder as capacidades metacognitivas e verbais, ficando sufocadas pelos seus medos no contexto avaliativo.

Durante a adolescência e com 0 advir do pensamento formal, 0 adolescente perceciona ainda mais (frequentemente sobrestimando) a discrepância existente entre aquilo que julga que os outros esperam de si e a visão de ineficácia que tem de si mesmo. Este processo cognitivo pode ser críti- 
co na perpetuação da ansiedade a exames, o que facilita o autofocus e a sensação antecipatória do escrutínio por parte dos outros. Este receio e desconforto em situações de avaliação deve-se ao facto da criança e adolescente recearem ser humilhados ou embaraçados nessas situações. Quando isto acontece, é gerada uma ansiedade antecipatória, e o indivíduo, habitualmente, quando entra na situação de exame revela já uma resposta ansiosa que é composta por uma componente vegetativa e (taquicardia, aumento da frequência respiratória, boca seca, sudação, tremor, etc.) e uma componente cognitiva (o pensamento destes indivíduos é focado sobretudo em pensamentos de fracasso ou incompetência); assim, o foco de atenção deixa de ser a tarefa a executar (i.e., o exame), passando o indivíduo a focar-se no seu desempenho, ou seja, entra em autofocus, o que revela duas consequências: 1) amplia a sua resposta emocional ansiosa; e 2) contribui para que ele funcione pior, dado que ao autofocar a atenção para si próprio, desvia a atenção que deveria estar focada na tarefa em si.

Na maioria dos indivíduos, uma das situações mais indutoras de stress é o dia do exame, bem como falar em situações de cariz mais formal (e.g., ter de comparecer numa avaliação oral ou apresentar oralmente um trabalho diante da turma e/ou do professor). Em adultos com ansiedade a exames as situações que mais despoletam ansiedade são situações de frequências, exames e avaliações orais, apresentação de teses, performances diante de outros, ou mesmo ler em voz alta (Smith, Arnkoff, \& Wright, 1990).

A investigação tem vindo a sugerir a importância dos fatores e processos cognitivos na experiência da ansiedade aos exames (Cruz, 1987). A natureza complexa e multidimensional deste distúrbio de ansiedade tem levado também alguns teóricos e investigadores a sugerirem a relevância de fatores e variáveis afetivas e emocionais (Sarason \& Sarason, 1990). Atualmente, a ansiedade aos exames é conceptualizada mais como um processo, do que como um fenómeno unitário e isolado no tempo. Cruz (1987) refere a importância de conceptualizar a ansiedade a exames como um grupo de fatores interrelacionados cujo papel no ciclo de realização varia de fase para fase, bem como de uma prova de avaliação para a seguinte. Menciona ainda que a compreensão deste fenómeno, e da sua relação com o rendimento escolar, exige a integração no contexto mais amplo do comportamento de realização. Neste sentido, ainda que por vezes através de diferentes perspetivas teóricas, tem sido salientada a necessidade de considerar a ansiedade a exames como um processo que inclui três fases ou etapas: antes da prova de avaliação, durante e depois. Por outro lado, os vários fatores de diferenças individuais parecem exercer um forte impacto nestes momentos distintos do ciclo de realização escolar.

Cruz (1989) alega para a necessidade de integrar as diversas perspetivas da ansiedade de forma a melhor compreender a ansiedade aos exames. Assim, esta poderá ser integrada no modelo transacional mais amplo do stress, ou seja, um processo transacional mediado cognitivamente. Enquanto a ansiedade a exames é perspetivada cognitivamente como ilustração do processo envolvido na antecipação de um confronto específico com a situação avaliativa e uma imobilização de "defesas" primitivas contra a ameaça (Beck, Emery, \& Greenberg, 1986), outros conceptualizam a ansiedade como uma reação ao stress, quando os indivíduos acreditam que as situações em que se encontram colocam exigências que excedem os seus recursos pessoais. De facto, "0 stress geralmente produz-se quando um indivíduo é incapaz de responder de forma adequada ou eficaz aos estímulos provenientes do seu meio ambiente, ou quando só o consegue à custa da saúde do seu organismo" (Dolan, García, \& Díez-Piñol, 2005, p. 21). Neste sentido, Cruz propõe um modelo compreensivo para a ansiedade a exames, acentuando a interação entre várias componentes: 1) uma primeira componente, a situação, envolve uma transação contínua entre a situação escolar e o estudante, entre as exigências ambientais e os recursos pessoais; 2) uma segunda componente inclui os processos de avaliação cognitiva e do processamento da informação, que ocupam um papel cen-

International Journal of Developmental and Educational Psychology 


\section{AI... VOU FAZER UM TESTE! CONSIDERAÇÕES EM TORNO DA ANSIEDADE A EXAMES}

tral e influenciam as respostas emocionais e comportamentais; 3 ) a terceira e última componente do modelo, a resposta à situação, engloba processos de confronto e comportamentos que constituem os esforços do estudante para lidar com a situação. Cruz (1989) fala ainda de estilos de avaliação cognitiva, que operam nos mecanismos de processamento da informação para ajudarem 0 indivíduo a criar o mundo psicológico em que se insere e vive, bem como a realidade psicológica a que responde.

Na sequência da "revolução cognitiva» operada em todos os domínios da psicologia, as conceptualizações cognitivas da ansiedade a exames (Sarason \& Sarason, 1990) têm recolhido uma atenção crescente da parte dos investigadores. 0 papel desempenhado pelos fatores cognitivos na relação entre a ansiedade aos exames e 0 rendimento escolar tem vindo a ser amplamente documentado e comprovado. Todavia, a natureza complexa e multidimensional da ansiedade a exames tem levado também alguns teóricos e investigadores a sugerirem a relevância de variáveis afetivas e emocionais. Mas concretamente, tem sido salientada a importância de ter em atenção as reações emocionais ao sucesso e ao fracasso nos contextos educativos. Por outro lado, parece existir suficiente consenso e evidência empírica para uma conceptualização global da ansiedade nos exames que inclui uma componente cognitiva e uma componente emocional (Cruz, 1987). Assim, podemos dizer que a ansiedade aos exames engloba as componentes emocional, fisiológica e cognitiva, esta última respeitante a: baixa autoconfiança e maximização das incertezas, antecipação do fracasso e das suas possíveis consequências, maximização da autocrítica, ideias de fugir ou evitar a situação de exame, interferência com a execução de exame, preocupação com o autoconceito e, por último, pensamentos intrusivos, disfuncionais e irrelevantes. Sarason e Sarason (1990) consideram a existência de cinco áreas da ansiedade a exames: (1) os componentes da ansiedade a exames, (2) a ansiedade a exames e o desempenho, (3) a interferência cognitiva, a preocupação e a inquietação do indivíduo, (4) a importância do autoconceito na aprendizagem e (5) os correlatos da ansiedade a exames.

No que respeita à investigação dos processos cognitivos e afetivos na ansiedade a exames, Cruz, nos finais da década de 80 (Cruz, 1987, 1989) explorou as diferenças entre estudantes universitários com altos e baixos níveis de ansiedade a exames antes, durante e depois da realização de um teste escolar universitário. 0 autor referia que persistiam duas importantes lacunas na investigação neste domínio. Uma primeira, de carácter mais teórico, reportava-se à falta de clareza no que respeita às diferenças entre os estudantes com altos e baixos níveis de ansiedade nos testes, especificamente no que se refere aos processos cognitivos. A segunda, mais de âmbito metodológico, prendia-se com a escassez de estudos que não se limitassem à análise do comportamento dos estudantes apenas numa ou duas fases adjacentes do processo de realização. Cruz (1987) realizou um estudo de natureza exploratória, pretendendo investigar antes, durante e depois de um teste escolar as diferenças nos processos e fatores cognitivos e emocionais entre estudantes universitários com altos e baixos níveis de ansiedade nas avaliações académicas. Em termos de fatores antecedentes, os resultados permitiram concluir que, em geral, os estudantes mais ansiosos reagiam aos testes com níveis significativamente mais elevados de tensão, preocupação, pensamentos irrelevantes para a tarefa e sintomas corporais, comparativamente aos estudantes menos ansiosos. Os estudantes mais ansiosos, para além de evidenciarem níveis mais elevados de desânimo em face das situações de exame, avaliavam os testes universitários mais negativamente. Considerando as diferenças antes da realização da prova, os alunos com baixos níveis de ansiedade experienciaram níveis significativamente mais baixos de preocupação imediatamente antes de se dar início à prova de avaliação e mostraram-se mais confiantes no que respeita à realização do teste. Não foram encontradas diferenças significativas entre ambos os grupos no que se refere à perceção da dificuldade do teste ou à classificação que esperariam obter. Após a realização do teste, não se observa- 
ram diferenças significativas entre os dois grupos no que respeita a dimensões causais (internalidade, estabilidade e controlabilidade), reações afetivas (afetos positivos e negativos) e, sobretudo, à nota obtida no teste e à perceção de sucesso/fracasso no teste. Os estudantes menos ansiosos atribuíram uma maior importância a fatores de ordem interna, particularmente ao esforço despendido (estudo ou falta dele). Para além da elevada frequência com que os alunos mais ansiosos nos testes atribuíram os seus resultados a um fator externo (e.g., dificuldade no teste), Cuz (1987) assinalou também a maior frequência (cerca de 30\%) com que 0 «nervosismo» serviu para explicar os resultados dos alunos com níveis mais elevados de ansiedade nas provas de avaliação. Estes, após a divulgação da classificação obtida, sentiam-se mais deprimidos, mais receosos e mais incompetentes, quando comparados com os menos ansiosos. Em face de perceção de fracasso, os dados sugerem que os estudantes mais ansiosos nos testes consideram as causas do seu rendimento como mais internas e estáveis, reagindo afetivamente de forma mais negativa relativamente aos alunos menos ansiosos nas provas de avaliação.

Turk e Sarason (1983) estudaram o rendimento académico nos diferentes indivíduos com ansiedade a exames, bem como a responsabilidade sentida por estes quando confrontados com o seu rendimento. Os autores verificaram que os indivíduos que faziam atribuições internas relativamente ao fracasso na tarefa apresentavam pouco rendimento subsequente em relação aos seus resultados. 0 melhor rendimento verificou-se nos alunos com atribuições internas e globais, do género: "considero-me um indivíduo com capacidades". Goldberg (1983) estudou a relação existente entre a ansiedade a exames e 0 estilo atribucional. Recorrendo ao Questionário de Estilos Atribucionais e à reação dos alunos aos testes, Goldberg concluiu que aqueles que tinham elevada ansiedade a exames tendiam a atribuir o sucesso na execução da tarefa a fatores externos e instáveis (locus de controlo externo). Inversamente, esses alunos apresentam um locus de controlo interno (fatores internos, gerais e estáveis) no que respeita aos fracassos nas situações de exame. Observemos o quadro que se segue (Cruz, Gonçalves, \& Machado, 1987), que nos alerta para o facto de uma fonte a não descurar no que respeita a diferenças individuais entre alunos com altos e baixos níveis de ansiedade nos testes é o estilo atribucional dos mesmos. Verifique-se, por exemplo, que os alunos com altos níveis de ansiedade nos testes nunca atribuírem o seu desempenho à falta de estudo, ao passo que os alunos com baixos níveis de ansiedade apresentaram essa justificação (22.7\%).

Quadro 1 - Percentagens das atribuições causais em alunos com altos e baixos níveis de ansiedade nos testes

\begin{tabular}{lcc}
\hline Atribuições & $\begin{array}{c}\text { Alunos com altos níveis de } \\
\text { ansiedade nos testes }\end{array}$ & $\begin{array}{c}\text { Alunos com baixos níveis } \\
\text { de ansiedade nos testes }\end{array}$ \\
\hline Estudo & 22.7 & 36.4 \\
Falta de estudo & 0.0 & 22.7 \\
Facilidade do teste & 4.5 & 0.0 \\
Dificuldade do teste & 18.2 & 4.5 \\
Atenção no teste & 0.0 & 4.5 \\
Falta de atenção no teste & 0.0 & 4.5 \\
Atenção nas aulas & 0.0 & 4.5 \\
Nervosismo & 27.5 & 4.5 \\
Interesse pela matéria & 4.5 & 9.1 \\
Sorte & 4.5 & 0.0 \\
Fadiga & 4.5 & 0.0 \\
Doença & 4.5 & 0.0 \\
Falta de tempo & 9.1 & 9.1 \\
\hline
\end{tabular}

(Fonte: Cruz et al., 1987, p. 306) 


\section{AI... VOU FAZER UM TESTE! CONSIDERAÇÕES EM TORNO DA ANSIEDADE A EXAMES}

Desde há muito que diversos autores se têm debruçado sobre as possíveis causas subjacentes aos níveis de desempenho escolar (Smith, Arnkoff, \& Wright, 1990). Todavia, esses estudos tomaram quase exclusivamente como fatores explicativos as variáveis intelectuais (Barros \& Almeida, 1991). Se ainda na atualidade tais variáveis se consideram, são agora tomadas novas orientações, das quais se salientam as experiências de aprendizagem, autoeficácia (Multon, Brown \& Lent, 1991), experiências educativas, variáveis de índole pessoal tais como as expectativas de locus de controlo, de desespero aprendido (Seligman, 1975; Roshenan \& Seligman, 1995), atribuições causais, etc. Barros e Almeida (1991), agrupam este conjunto de variáveis sob a designação de variáveis sociocognitivas.

Cruz (1988) refere algumas características ou tendências individuais relativamente estáveis e generalizadas que tornam os alunos mais predispostos a agirem ou pensarem de determinadas formas, podendo atuar como fatores de risco ou antecedentes causais da experiência de ansiedade aos exames, tais como: traço de ansiedade aos exames, tendência para reagir com estados de ansiedade nos testes, desânimo aprendido e estrutura cognitiva dos alunos. É também sabido que no período que antecede imediatamente as situações de avaliação, está demonstrada a importância de fatores como o nível de expectativas, a perceção da dificuldade da prova de avaliação, o nível de autoconfiança e o estado de ansiedade experienciado, ou seja, os níveis de preocupação e emoção.

Sarason e Sarason (1990) apontam para os fatores responsáveis pelo decréscimo ao nível do desempenho em indivíduos com ansiedade de desempenho a exames: pensamentos intrusivos relacionados com preocupações acerca do desempenho com a tarefa que levam a uma dispersão da tarefa para o self, dificuldades em organizar o material a aprender, aptidões de estudo inadequadas, aptidões para lidar com as situações de avaliação inadequadas, pressão temporal e instruções orientadas para o desempenho. Cruz (1988) alerta para o papel preponderante que os pensamentos intrusivos ocupam na diminuição da performance do indivíduo, apontando para o facto de que, quanto mais negativo 0 diálogo interno, mais baixa será a probabilidade de ser bem-sucedido e maior 0 nível de ansiedade. Atente-se a alguns dos pensamentos dos alunos relacionados com a preocupação acerca do desempenho (e.g., "nunca irei conseguir") e da comparação que fazem com os pares (e.g., "são todos melhores do que eu"), conduzem por vezes a desviar a atenção para assuntos não relacionados com a tarefa de estudo.

Matos, Canavarro e Vaz Serra (1996), analisaram 255 estudantes do ensino superior, chegando à conclusão de que os alunos que manifestavam ansiedade mais significativa aos exames tendiam a apresentar médias académicas mais baixas. Foi igualmente constatado um índice superior de reprovações. Dias e Vaz Serra (1998) referem as seguintes consequências da ansiedade a exames, uma vez evocada e fixada: 0 aluno passa a considerar as situações em que vai ser avaliada como difíceis e ameaçadoras; sente-se inapto e inseguro perante elas e, segundo Sarason e Sarason (1990), passa a ter preocupações quanto ao futuro e às consequências indesejáveis que a sua incapacidade acarreta; espera e antecipa o fracasso em tais circunstâncias; por seu turno, este mesmo facto propicia respostas de fuga e de evitamento das situações de avaliação temidas. Assim, 0 aluno fica mais propenso a desistir durante as avaliações, acabando mesmo por evitar algumas delas, 0 que impede a progressão académica. Dias e Vaz Serra (1998) apontam ainda para uma diminuição da tolerância à frustração. Dito de outro modo, o sujeito impacienta-se e irrita-se mais facilmente. A ansiedade que sente provoca-Ihe um estado de apreensão, alarmando-se com as consequências trágicas que lhe poderão acontecer. No que respeita à atenção, o indivíduo revela mais dificuldades em detetar erros nas tarefas que exigem uma atenção permanente, cometendo um maior número de erros nas respostas a tarefas simples, quando existe sobreposição de vários estímulos.

Para finalizar, apresentamos um esquema retirado de Freeman, Pretzer, Fleming e Simon (1990), que ilustra o papel das cognições em psicopatologia, que adaptamos com exemplos de pensamentos típicos em casos de ansiedade a exames. 


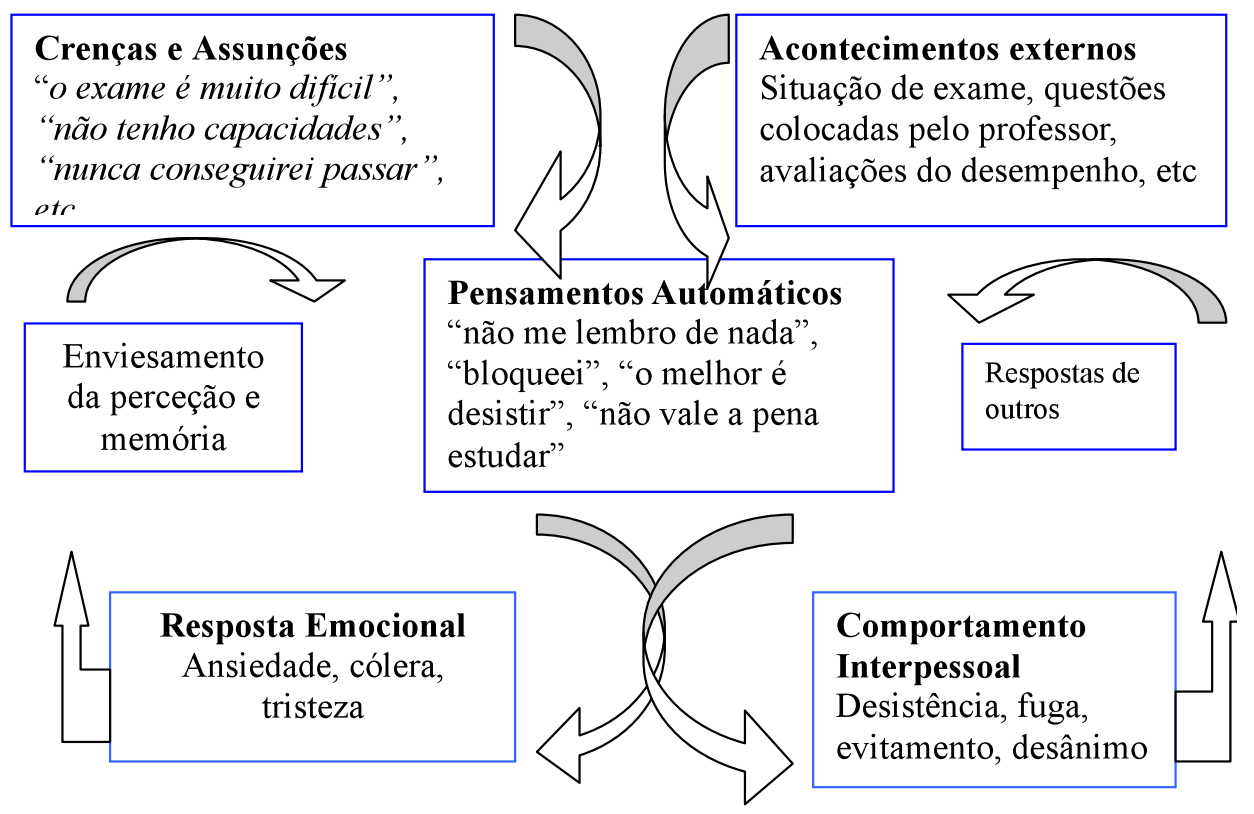

(Adaptado de Freeman, Pretzer, Fleming, \& Simon, 1990, p. 7)

De facto, a ansiedade de desempenho a exames é um fenómeno complexo, envolvendo diferentes variáveis (cognitivas, emocionais, motivacionais e comportamentais), derivando daqui a diversidade de abordagens, sendo, na nossa opinião, a mais pertinente aquela que encara a ansiedade a exames como um «processo mediado cognitivamente». Na verdade, tal como Freeman et al. (1990) reconhecem, o modelo cognitivo não refere simplesmente que "os pensamentos causam sentimentos e ações", mas também que as emoções podem influenciar os processo cognitivos e os comportamentos a avaliação de uma dada situação. Constata-se, também, uma grande influência do humor na cognição. Os pensamentos automáticos negativos, as assunções subjacentes, as distorções cognitivas, bem como o impacto do humor na cognição combinam-se no estabelecimento de um ciclo autoperpetuador, patente na ansiedade a exames.

\section{CONSIDERAÇ̃̃ES FINAIS}

A ansiedade a exames não é uma reação simples e unificada a uma ameaça percebida, e sim a um grupo de fatores cujas várias ligações ao rendimento nos exames variam à medida que 0 aluno progride através do ciclo da realização, desde um estádio de preparação para a situação de avaliação do seu desempenho até à sua realização e, finalmente, para uma fase de reação ao exame (Covington, 1985). Portanto, deve ter-se sempre presente não só o que acontece durante mas também depois. Ainda, é de salientar a transação contínua entre 0 aluno e a situação escolar, determinando reações de ansiedade e não descurando os processos de avaliação cognitiva e respostas de confronto com a situação. Portanto, a ansiedade às situações de exames não deve ser encarada como uma mera característica da situação ou do estudante. Ela resulta não das pro- 


\section{AI... VOU FAZER UM TESTE! CONSIDERAÇÕES EM TORNO DA ANSIEDADE A EXAMES}

priedades objetivas da situação, mas antes da interpretação ou avaliação cognitiva que 0 aluno faz da mesma.

Consideramos que na ansiedade a exames existe mais do que uma simples história de experiências de fracasso. Há que analisar a interação contínua entre 0 aluno e a situação de teste, não descurando os processos de avaliação cognitiva e respostas de confronto com a situação. Já em 1979, Clifford Allen afirmava: "todo o êxito na vida depende de dois elementos: a inteligência e 0 afã de triunfar. (...) quer estejamos de acordo ou não, e como não podemos modificar o sistema, temos de aceitá-lo. Assim, o que há de mais vantajoso (...) é conseguir passar nos exames" (Allen, 1979, pp. 11-13).

Terminamos a nossa abordagem com uma citação livre de Sarason (1980), que refere que a ansiedade de desempenho a exames tem sido um pouco como o tempo: todo a gente fala nele, mas ninguém 0 consegue alterar.

\section{REFERÊNCIAS}

Abreu, M. V., Leitão, L. M., Santos, E. R., \& Paixão, M. P. (1988). Mobilização de potencialidade de desenvolvimentos do sucesso escolar. Psychologica, 1, 1-26.

Allen, C. (1979). Passing school examinations: A book for parents. Londres: Edições Ponte.

Barros, A. M., \& Almeida, L. S. (1991). Dimensões sócio-cognitivas do desempenho escolar. In Almeida, L. S. (Ed.). Cognição e aprendizagem escolar. Porto: Associação dos Psicólogos Portugueses.

Barros, A., Barros, J. \& Neto, F. (1988). Locus de controlo e motivação para a realização. Psychologica, 1, 57-69.

Beck, A. T., Emery, G., \& Greenberg, R. (1985). Anxiety disorders and phobias: A cognitive perspective. New York: Basic Books

Burns, R. (1982). Self-concept development. Great Britain: Dorset Press.

Covington, M. V. (1985). Test Anxiety: causes and effects over time. In H. Vander Ploeg \& C. D. Spielberg (Eds.), Advances in test anxiety research (Vol. 4, pp. 55-68). Hillsdale, NJ: Erlbaum.

Cruz, J. F. (1988). Uma abordagem cognitiva e transaccional à ansiedade nos testes e exames escolares. Jornal de Psicologia, 7(3), 3-9.

Cruz, J. F. (1989). Incidência, desenvolvimento e efeitos da ansiedade nos testes e exames escolares. Revista Portuguesa de Educação, 2(1), 111-130.

Cruz, R. A. Gonçalves, \& P. P. Machado (1989).(Eds.). Psicologia e educação. Porto: Associação dos Psicólogos Portugueses.

Dendato, K. M., \& Diener, D. (1986). Efectiveness of cognitive/relaxation therapy and study-skills training in reducing self-reported anxiety and improving the academic performance of test-anxious students. Journal of Counseling Psychology, 33(2), 131-135.

Dias, I. S., \& Vaz Serra, A. (1998). Ansiedade em exames e insucesso escolar. Psiquiatria Clínica, 19(2), 77-82.

Dolan, S. L., García, S., \& Díez-Piñol, M., (2005). Autoestima, estrés y trabajo. Madrid, SP: McGrawHill.

Freeman, A., Pretzer, J., Fleming, B. \& Simon, K. (1990). Clinical applications of cognitive therapy. New York: Plenum Press.

Goldberg, S. A. (1983). Cognitive correlates of test anxiety: Examination of the relationship among test anxiety, fear of negative evaluation, social anxiety, and attributional style. Unpublished honors thesis. USA: Brown University.

Gouveia, J. A. (1997). Fobia Social: conceito, critérios de diagnóstico, epidemiologia e características clínicas", Psiquiatria Clínica, 18(4), 279 - 293. 
March, J. (1995). Anxiety disorders in children and adolescents. New York: Guilford Press.

Matos, A. P., Canavarro, C., \& Vaz Serra, A. (1996). Ansiedade aos exames: Relação com a ansiedade social, 0 auto-conceito e as estratégias de resolução de problemas. Psiquiatria Clínica, 17(4), 337-346.

Multon, K. D., Brown, S., \& Lent, R. W. (1991). Relation of self-efficacy beliefs to academic outcomes: A meta-analytic investigation. Journal of Counseling Psychology, 38(1), 30-38.

Pennings, A. H., \& Span, P. (1991). Estilos cognitivos e estilos de aprendizagem, In Almeida, L. S. (Ed.). Cognição e aprendizagem escolar (pp. 99-125). Porto: Associação dos Psicólogos Portugueses.

Rosenhan, D. L., \& Seligman, M. E. (1995). Abnormal Psychology (3rd ed.). New York: W. W. Norton \& Company.

Sarason, I. G., \& Sarason, B. R. (1990). Test anxiety. In H. Leitenberg (Ed.). Handbook of social and evaluation anxiety. New York: Plenum Press.

Sarason, L. (1980) - Introduction to the Study of test. In I. G. Sarason (Ed) Test Anxiety: Theory research and aplications. New Jersey: Lawrence Erlbaum Associates.

Seligman, M. (1975). Helplessness. San Francisco: Freeman.

Smith, R. J., Arnkoff, D. B., \& Wright, T. L. (1990). Test anxiety and academic competence: A comparison of alternative models. Journal of Counseling Psychology, 37 (3), 313-321.

Turk, S., \& Sarason, I. (1983). Test anxiety and causal attributions. Seattle: University of Washington.

Vaz-Serra, A. S. (1988). Atribuição e autoconceito. Psychologica, 1, 127-141.

Veiga, F. H. (1989). Autoridade paterna, auto-conceito e rendimento escolar. In J. F. Cruz (Ed.), Psicologia e educação: Investigação e intervenção. Porto: Associação dos Psicólogos Portugueses. 
